\title{
Journal of Emergency Primary Health Care
}

www.jephc.com

ISSN 1447-4999

ORIGINAL RESEARCH

Article 990218

\section{A Descriptive Physical Profile of Western Australian Male Paramedics}

\author{
D. Chapman, J. Peiffer, C. R. Abbiss, P. B. Laursen \\ School of Exercise, Biomedical and Health Sciences \\ Human Performance Centre \\ Edith Cowan University \\ AUSTRALIA
}

Objectives: The purpose of this investigation was to evaluate the physical characteristics of a group of West Australian male paramedics.

Methods: Data was collected from conventional (CO) $(n=18)$ and special operations (SO) $(n=11)$ officers undergoing occupational performance evaluations as contracted by St. John Ambulance Australia to an external independent third party. Using a series of field-based physical conditioning tests, aerobic capacity (multistage shuttle run test), body composition (skinfolds), flexibility (sit-and-reach test), muscular strength (5 stage abdominal and grip strength), muscular endurance (sit-ups, push-ups and chin-ups in 60 seconds (s)), power (vertical jump height), and anaerobic capacity/agility using the Bangsbo agility test were examined.

Results: The average predicted aerobic capacity of all officers was $45.8 \pm 5.2 \mathrm{ml} \cdot \mathrm{kg} \cdot \mathrm{min}^{-1}$ (mean \pm SD). Mean rating of abdominal strength was $4 \pm 1$ and mean grip strength was $52 \pm 9$ $\mathrm{kg}$. The maximum number of sit-ups, push-ups and chin-ups performed in $60 \mathrm{~s}$ was $21 \pm 11$, $40 \pm 12$ and $7 \pm 5$, respectively. Significantly more push-ups were completed for SO than for CO. Percentage body fat was significantly lower for SO than for CO. Fatigue index score (Bangsbo test) were significantly lower for SO than for CO.

Conclusions: The physical fitness profile of our sample indicated above normal levels of aerobic capacity, local muscle endurance and muscle strength, which likely contributes to workplace performance competency. However the fitness profile highlighted a potential deficiency in anaerobic capacity. Paramedics may benefit from a physical conditioning program with emphasis on their ability to operate at a greater functional capacity for higher repeated near maximal efforts.

Key Words: aerobic capacity; Bangsbo agility test; emergency services; physical fitness 


\section{Introduction}

The physical fitness characteristics of firefighters, ${ }^{1,2}$ police officers ${ }^{3}$ and armed service personnel $^{4}$ are well-documented. In contrast, a relative paucity of data is available describing the physical attributes of emergency medical services personnel. ${ }^{5}$ This is despite the challenging physical ${ }^{6}$ and mental ${ }^{7,8}$ requirements of the occupation. Indeed, stressors experienced by paramedics include high physical exertion during prolonged manual cardiopulmonary resuscitation, ${ }^{9}$ heavy lifting manoeuvres involved with patient $\operatorname{transfer}^{6}$ and the mental strain associated with trauma situations ${ }^{8}$ and shiftwork. ${ }^{10}$ As a result, occupational proficiency as a paramedic requires above average levels of aerobic ${ }^{9}$ and anaerobic fitness ${ }^{5,6}$ coupled with adept cognitive function. ${ }^{5}$ Although there is a shortage of information specifically pertaining to paramedics, this may be due to the fact that some paramedics may also be members of other emergency service personnel, and as such may be described elsewhere.

Despite the high physical demands associated with the paramedical occupation, ${ }^{5}$ a fitness profile of paramedics, and in particular the description of two distinct groups of paramedics, has not been reported. Therefore, the purpose of this study was to describe the physical fitness characteristics of active male paramedics, as well as a select group of special operations paramedics, using an array of cost-effective field-based measurements.

\section{Methods}

\section{Subjects}

Participants for the study included 29 male paramedics employed by St John Ambulance Australia, which consisted of two groups: of the first was 18 conventional metropolitan officers (CO) (38.1 $\pm 6.5 \mathrm{yrs} ; 1.8 \pm 0.1 \mathrm{~m}$ and $88.0 \pm 11.9 \mathrm{~kg})$ and of the second was 11 Special Operation officers (SO) (38.2 $\pm 4.3 \mathrm{yrs} ; 1.8 \pm 0.1 \mathrm{~m}$ and $84.3 \pm 10.6 \mathrm{~kg}$ ). Although these groups are considered separate for the purposes of this research, the special operations officers were actively serving in conventional metropolitan positions. Officers volunteered for testing either as part of an annual fitness assessment (Special Operation group members), or to be considered for selection into the Special Operations group. The presentation of results is intended to provide a guiding description of the physical characteristics of Western Australian male paramedics. A sample size calculation was not performed, however profiling of specific athletic sub-populations have previously been reported using a smaller or similar sample size. ${ }^{11}$ Further, the subject number used in this study represented approximately $10 \%$ of the employed workforce. All participants provided written informed consent to be subjects for this study and the research was conducted in accordance with the guidelines provided by the Declaration of Helsinki pertaining to research using human subjects.

\section{Procedures and protocol}

The development of pre-employment and in-service physical ability tests has been conducted using fire fighters and law enforcement officers. Testing is normally developed following occupational task analysis and surveying of current personnel. Considine and co-workers ${ }^{2}$ identified the physical components of dynamic strength, static strength, agility, total body coordination, cardio-respiratory endurance, muscular endurance, eye-hand coordination and total body speed to be necessary for a fire fighter to successfully perform their duties. Similarly Davis et al. ${ }^{12}$ proposed the physical performance measures of body composition, general fitness, aerobic fitness and cardiovascular variables as key physical components. Based on that assessment, the investigators used the field assessments of push-ups, sit-ups, grip strength, percentage body fat (skin-folds), lean body weight and an estimated $\dot{\mathrm{V}} \mathrm{O}_{2 \max }$ from a step test to determine overall physical work capacity. 
For the present study, the fitness tests selected represent important physical capacities of occupationally competent paramedics; we believed these capacities would be similar to those displayed by fire fighters and law enforcement officers. The following fitness components were chosen and examined for each subject in the following order on the testing day:

1. aerobic capacity

2. anthropometry

3. flexibility

4. muscular strength

5. muscular endurance

6. muscular power

7. agility/anaerobic capacity

These fitness components are routinely measured when assessing the physical capacities of elite level athletes. All testing was administered by four qualified Exercise Physiologists. Subjects progressed through the test protocol in such a way that the muscle group or system being stressed was provided with adequate recovery between tests. Subjects reported to the testing site to begin their battery of tests at 7:30 am. Subjects were asked to avoid exercising the day prior to the tests and to report 2 hours postprandial and in a hydrated state. Testing was completed over two days with all CO participants tested on the first day and all SO participants on the second day.

Aerobic capacity

A standard multistage shuttle run test was performed by each subject in standard laboratory conditions $\left(\sim 20^{\circ} \mathrm{C}\right)$ and was used to provide a prediction of the subject's aerobic capacity $\left(\mathrm{V}_{2 \max }\right)$. The test consisted of progressive increases in running speed over a $20 \mathrm{~m}$ distance, with the running velocity for each $20 \mathrm{~m}$ distance dictated by audible 'beeps' (Australian Sports Commission, Canberra, Australia). Each subject was required to complete the $20 \mathrm{~m}$ distance before each audible 'beep' occurred, turn $180^{\circ}$ and again complete the $20 \mathrm{~m}$ in the opposite direction before the next audible 'beep'. This scenario was repeated by the subject until exhaustion, which was defined by the inability of subject to cover the $20 \mathrm{~m}$ distance before an audible beep on two consecutive occasions. This test is strongly linked to direct measures of aerobic capacity ${ }^{13}$ and is commonly used as a field-based assessment of aerobic capacity in Australia.

\section{Anthropometry}

Measurements of height, body weight and skinfold thickness at seven sites were sampled on each participant. The sum of seven skinfolds was used to estimate the percentage body fat of each participant. Skinfold measurements were assessed using handheld skinfold callipers (Harpenden; Model: HSK-BI. United Kingdom) measured at seven sites: chest, midaxillary, triceps, subscapular, abdomen, suprailiac and thigh. Standard calculations for body mass index (BMI) and percentage body fat were determined. ${ }^{14}$ Prior to the anthropometric measures, subjects had at least 20 min to cool down and towel off any sweat accumulated during completion of the 'Beep test'.

\section{Muscular strength, endurance and power}

Measurements of grip strength from right and left hands were performed using standard grip strength assessment techniques. Subjects were positioned with their heels and shoulders against a wall and were instructed to fully extend their arm overhead. Subjects were then instructed to maintain full extension of their arm and lower their arm while squeezing a handheld dynamometer (Smedley's 0-100 kg, England) in a steady motion (to a count of $3 \mathrm{~s}$ ) 
and to finish at their side. This was repeated 3 times, with 30 s rest taken between efforts, and the best effort recorded as the subject's grip strength score.

Abdominal strength was assessed using a five-stage sit-up test of progressive difficulty. Stage 1 required the participant to perform a pelvic tilt while lying flat on the ground. Stages $2-5$ were conducted with the knees bent $\left(\sim 90^{\circ}\right)$ and the feet flat on the ground. Stage 2 involved the subject curling upward and forward with their palms face down on the ground while the examiner applied pressure to the feet so that their chest came into contact with their knees. For successful completion of Stages 3-5 subjects were instructed to keep their feet flat on the ground during the entire sit-up movement; each movement was considered complete when the subject's chest came into contact with their knees. Stage 3 was similar to Stage 2, except that the examiner did not apply downward pressure to the participant's feet. Stage 4 required the subject to place the palm of each hand on their opposite shoulder when they performed the situp, while Stage 5 required the subject to place their fingertips behind their ears (not gripping behind the head) and to perform a single sit-up. Each participant's score was the last successfully completed stage; failure to complete a stage was defined as the inability to perform a successful sit-up, which included lifting of the feet off the ground. At the completion of the staged abdominal strength test, subjects were seated for 3 min before beginning the muscle endurance assessment.

Muscular endurance was assessed using a timed $60 \mathrm{~s}$ sit-up and a $60 \mathrm{~s}$ push-up test. Subjects were instructed to complete their sit-ups using the Stage 3 technique described above; subjects unable to reach Stage 3 were awarded a score of zero. Push-ups were performed in a standard three point position. One push-up was awarded when the subject completed movement from a starting position (straight arms) down to $90^{\circ}$ elbow flexion, and then returned to the starting position; if $90^{\circ}$ elbow flexion was not achieved, then a push-up was not awarded. Total number of completed sit-ups and push-ups achieved in the $60 \mathrm{~s}$ period was used in the analysis. Subjects recovered passively for 3 min between the sit-up and push-up muscle endurance tests and prior to the beginning of the upper body strength assessment.

Upper body strength was measured using a timed 60 s pull-up (chin-up) test. Subjects began from a fully extended elbow position with a forward facing grip, and were asked to raise their body weight to a position where their chin was equal to or above the chin-up bar before returning to the extended elbow position. Completion of one successful movement sequence was considered as one pull-up. If the subject did not hold the finishing position (if they released the bar) then the chin-up was not awarded. Total completed pull-ups achieved in $60 \mathrm{~s}$ were used in the analysis.

Maximal leg power was assessed using a vertical jump test on a force platform (Quattro jump portable force plate - A9290AD; Kistler Instruments, Inc., Amherst, NY). Jump height was calculated using the Quattro Jump@ software program. Three jumps were performed using a counter movement position without arm involvement (no swinging of the arms prior to takeoff). Subjects were instructed to have their hands remain in contact with their hips during all jumps. Passive recovery of $60 \mathrm{~s}$ was allowed between each maximal jump effort and the maximal jump height recorded was used in the analysis.

\section{Flexibility}

Flexibility was assessed using a 'sit-and-reach' test. While a specific warm-up was not conducted directly before this test, the test was performed approximately 30 min following completion of the multistage fitness test. With shoes removed, participants sat with their legs fully extended with the soles of their feet against a standard sit-and-reach box (zero point set 
at $0.23 \mathrm{~m}$ ). Subjects were instructed to perform a smooth forward curling action with both hands overlayed (parallel) in front of them. Subjects were instructed to momentarily hold that position when maximal flexion was achieved. If bouncing was observed near the peak range of motion, that effort was not recorded. The best of three trials was recorded as the sit-andreach flexibility score with $30 \mathrm{~s}$ of rest in between trials.

\section{Agility and anaerobic capacity}

Agility and anaerobic capacity were assessed using the Bangsbo agility test ${ }^{15}$ and testing was carried out following 10 min passive rest at the completion of all other testing components. Briefly, participants were required to negotiate through a predetermined $40 \mathrm{~m}$ course (right side only change of direction) within a $25 \mathrm{~s}$ time period, 7 consecutive times on a non slip court surface. Timing of the sprint sections was performed using infrared timing gates and the Kinematics Measurement Systems software (Innervations Inc., Adelaide, Australia). The $25 \mathrm{~s}$ return phase was controlled using a standard stopwatch and verbal instructions. Three measures were determined for each subject from each set of sprint-agility trials:

1. the 'Fastest' time, which was the fastest time of all seven trials

2. the 'Mean' time, which was an average of the seven trials, and;

3. a 'Fatigue' index, calculated as the difference between the slowest and fastest times (expressed as a percentage).

\section{Statistics}

All data are presented as means \pm standard deviations, with $90 \%$ confidence intervals provided. Comparison of differences in measurements obtained between conventional metropolitan officers (CO) and special operation officers (SO) were analysed using a Student's t-test with the significance level set at $\mathrm{P}<0.05$. Where normalized population data existed, a Student's t-test was used to analyse differences between values measured in both the CO and SO groups compared to a population norm.

\section{Results}

The predicted aerobic capacity of the ambulance officers is shown in Table 1 . The mean $\dot{V} O_{2 \max }$ for all of the officers was $45.8 \pm 5.2 \mathrm{ml} \cdot \mathrm{kg} \cdot \mathrm{min}^{-1}$. While the CO group tended to have a lower $\dot{V} \mathrm{O}_{2 \max }$ than the SO group, this difference was not statistically significant $(\mathrm{P}=0.054)$. As well, both $\mathrm{CO}$ and $\mathrm{SO}$ group values for aerobic capacity were significantly greater than population normative values $\left(41.0 \mathrm{ml} \cdot \mathrm{kg} \cdot \mathrm{min}^{-1}\right.$; $\left.\mathrm{P}<0.05\right)$.

Anthropometric and body composition data of the ambulance officers are presented in Table 1. Age, height and weight were similar across groups. CO group measurements for BMI were significantly larger than population normative values $\left(24.9 \mathrm{~kg} / \mathrm{m}^{2}\right)$, however when compared with the SO group, no significant differences existed. Body fat composition for the SO group was significantly less than normative population values (19.0\%), but CO body fat composition was not. Between group comparisons also revealed that body fat percentage for the SO group was significantly less than that of the CO group $(\mathrm{P}<0.05$; Table 1$)$.

Muscle strength, endurance and power of the ambulance officers are summarised in Table 1. No statistical differences were observed between CO and SO groups in their grip strength, however the SO group demonstrated greater abdominal strength than the CO group $(\mathrm{P}<$ 0.05). Tests of muscular endurance indicated no differences between groups for sit-ups or 
pull-ups, however the SO group values for push-ups were significantly greater than that of the CO group $(\mathrm{P}<0.05)$.

Sit-and-reach scores are shown in Table 1 . Both groups showed statistically greater flexibility compared with standard population normative values $(25 \mathrm{~cm})$, with a trend being shown towards greater flexibility in the SO compared with the CO group $(\mathrm{P}=0.06)$.

The Bangsbo anaerobic agility test scores are shown in Table 1. No statistical differences were observed between the groups for the fastest or average time, however fatigue index values for the SO group were statistically less than those of the CO group ( $\mathrm{P}<0.05)$.

\section{Discussion}

To the best of the author's knowledge, the present study is the first to describe the physical characteristics of both conventional and special operation emergency medical service personnel using practical field-based measurements of physical fitness. An important finding was that despite the high physical and mental work demands placed upon paramedics, ${ }^{6-8}$ the mean physical attributes of standard paramedics measured in this study only differed from that of the general public for their aerobic capacity and flexibility. However, the special operations group of paramedics in the present study were found to possess superior mean levels of muscular endurance and aerobic capacity compared with that of the public and conventional paramedics. These findings must be treated with caution however as they may not be representative of the total Western Australian paramedical workforce. Moreover, for the metropolitan officer group in the present study, the physical testing they performed formed part of a wider screening process for positional movement into the special operations section. It is therefore possible that this group of participants may have possessed higher than normal levels of motivation to succeed in these tests in order to gain selection for the special operations group, possibly biasing their testing scores.

Anthropometric assessment of the paramedics from the present study (Table 1) are similar to results reported for other emergency medical service personnel. ${ }^{1,3}$ Despite being similar to levels reported in male police $(\sim 18 \%)^{3}$ and military officers $(\sim 19 \%),{ }^{4}$ the percentage body fat of standard officers was significantly greater than that of the special operation officers (Table 1 ) and those previously reported for firefighters $(\sim 14 \%) .{ }^{1}$ Comparison between CO and SO groups indicated that the SO group had significantly lower levels of body fat when compared with the CO group. However the lack of a significant difference in aerobic capacity suggests that these two variables may not share a common relationship. Furthermore, during normal ambulance rescue duties, body fat may prove to be a more important physiological variable to ambulance officers than aerobic capacity. While many tasks are completed below maximal aerobic levels (i.e., cardiopulmonary resuscitation, patient handling, etc), ${ }^{5}$ increased levels of body fat may lead to an increase in the relative intensity of such activities. ${ }^{16}$ Under circumstances of prolonged duty, as undertaken in situations experienced by SO officers, increases in the relative exercise intensity may lead to premature fatigue and the inability to perform the required duties competently. The efficacy of this outcome is demonstrated through the significantly lower fatigue index shown in the SO group (Table 1). Therefore, annual screening for body composition in both CO and SO may assist in ensuring effective task competency and the provision of high quality of care. Interestingly, our finding of no significant difference between CO and SO on the BMI measure may indicate the lack of sensitivity of this measure questions it's use as a screening tool. It should be noted that in any population group a high BMI score might still represent a high cardiovascular risk because any large mass whether muscle or fat may still increase physiological strain on the body 
during physical activity. Indeed, it is possible that individuals with a high quantity of fat-free mass (which would result in a high BMI score) could be unjustifiably excluded if BMI were the sole discriminator. Future research investigating the physical competencies of paramedics could focus on determining the levels of body fat where occupational performance declines.

Limited data is currently available on the aerobic capacity of paramedics, which is a surprising disparity as cardiopulmonary resuscitation (CPR $)^{9,17}$ has been demonstrated to have a high aerobic component. ${ }^{5}$ Interestingly, the predicted $\dot{\mathrm{VO}}_{2 \max }$ of the standard paramedics tested in this study (Table 1) were similar to those previously reported for male paramedics (43 $\left.\mathrm{ml}^{1} \mathrm{~kg}^{\prime} \mathrm{min}^{-1}\right)^{6}$ and significantly higher in both CO and SO compared with the general population average $\left(41.0 \mathrm{ml} / \mathrm{kg} \mathrm{min}^{-1}\right) .{ }^{18}$ While no statistically significant differences were recorded for estimated $\dot{\mathrm{VO}}_{2 \max }$ between $\mathrm{CO}$ and $\mathrm{SO}$ officers $(\mathrm{P}=0.054)$, differences in fatigue index during the Bangsbo agility test suggest that possible differences in aerobic capacity may exist between the groups. While we acknowledge that CPR is best performed in short rotations between available personnel in order to minimise fatigue, a greater aerobic capacity will permit a more prolonged effort and provides faster recovery between subsequent efforts.

Measures of muscular strength, muscular power and indicators of agility did not vary statistically between conventional or special operations paramedics. However, the importance of muscular strength on the performance of paramedics has previously been shown. ${ }^{6}$ Further research is needed to ascertain the influence of power, flexibility and agility on the performance and safety of paramedics to determine the necessity of including such aspects in future physical fitness testing and the development of specific paramedic conditioning programs. Furthermore, before specific testing and conditioning programs can be developed, researchers and industry management must establish the relationships between the various elements of fitness we have identified and workplace physical demands. It is possible that more specific physical occupation tests could be developed to improve the validity of testing for paramedic workplace competency.

Results from the present study provide a rationale for the routine testing and conditioning of paramedics in order to improve and maintain physical health, enhanced work performance ${ }^{6}$ and reduced other work-related health concerns. ${ }^{19}$ Furthermore, pre-employment and regular occupational testing of aerobic capacity may provide a basis for minimal entry requirements as well as providing baseline data for the development of an employment conditioning program. The results however only provide a starting point for the development of regularly scheduled testing protocols. Moreover, due to the small sample size used in the present study, these results should only be used as a guide, and not a delineation point for future employment testing. Further research is needed to develop normative values for use in screening procedures and these should be validated with task analysis and consultation with active paramedics.

The information described by this research is of specific interest to human resource management, current paramedics and those potential officers. The physical profile described provides a more in depth estimation of the job requirements of a paramedic than that contained in a pre-employment medical questionnaire. While the field-based testing described herein will in no way replicate the situations officers experience when performing their duties, the tests do provide an estimation of the physical systems that officers will utilise when they perform their workplace duties. The profile is however lacking, as we did not have access to female officers, which make up approximately one-third of the workforce in Australia. Future 
research is required with an adequate gender mix to fill this void if the physical assessment of ambulance officers becomes commonplace.

It is appreciated that the time available for devotion to a physical strength and conditioning program for active paramedics is limited; additionally the resources for effective training could also be scarce. However, time effective methods such as interval training for increasing both aerobic/anaerobic capacity and reducing fatigability have been demonstrated to be effective in athletic populations. ${ }^{20-22}$ To further enhance gains made in general conditioning, a structured and periodised program such as that recommended by the American College of Sports Medicine is advised. ${ }^{23}$ The increases that could be achieved in a paramedic's anaerobic capacities through anabolic exercise ${ }^{24}$ could prove to be of greater benefit in care provision and in the prevention of workplace structural-soft tissue injuries. It should also be noted that increases in physical fitness levels lead to decreases in sick leave, increased job performance ${ }^{1,6}$ and lowered workplace accidents. ${ }^{19}$ An employer's ability to retain qualified paramedics by providing an environment that improves job satisfaction through the health benefits of structured, periodised on the job physical conditioning sessions may increase the retention of experienced paramedics and improve community service.

In conclusion, this investigation provides a description of the physical attributes of standard and special operations ambulance officers of Western Australia. The anthropometric and aerobic measures recorded here indicate that Western Australian paramedics are comparable to other emergency medical service professions. Results from anthropometric testing, and aerobic/anaerobic testing provides the basis for exercise physiologists and strength and conditioning specialists to develop appropriate conditioning programs aimed specifically at improving cardiovascular fitness and muscular strength/endurance of paramedics. It is proposed that these results may also be used for the development of minimal entry requirements necessary for emergency medical service personnel. However, further research is needed to assess the occupational physical requirements of paramedics in order to determine whether standard physical tests are adequate assessors of workplace performance capacities, or whether specific occupational tests are needed. 


\section{References}

1. Williford HN, Duey WJ, Olson MS, Howard R, Wang N. Relationship between fire fighting suppression tasks and physical fitness. Ergonomics. 1999;42(9):1179-86.

2. Considine W, Misner JE, Boileau RA, Pounian C, Cole J, Abbatieilo A. Developing a physical performance tests battery for screening Chicago firefighting applicants. Pub Pers Mgt. 1976;5:7-14.

3. Copay AG, Charles MT. Police academy fitness training at the Police Training Institute, University of Illinois An International Journal of Police Strategies and Management. 1998;21(3):416-31.

4. Friedl KE, Leu JR. Body fat standards and individual physical readiness in a randomized Army sample: screening weights, methods of fat assessment, and linkage to physical fitness. Military Medicine. 2002;167(12):994-1000.

5. Gamble RP, Stevens AB, McBrien H, Black A, Cran GW, Boreham CA. Physical fitness and occupational demands of the Belfast ambulance service. British Journal of Industrial Medicine. 1991 Sep;48(9):592-6.

6. Barnekow-Bergkvist M, Aasa U, Angquist KA, Johansson H. Prediction of development of fatigue during a simulated ambulance work task from physical performance tests. Ergonomics. 2004;47(11):1238-50.

7. van der Ploeg E, Kleber RJ. Acute and chronic job stressors among ambulance personnel: predictors of health symptoms. Occupational and Environmental Medicine. 2003;60 Suppl 1:i40-6.

8. Young KM, Cooper CL. Occupational stress in the ambulance service: a diagnostic study. Health Manpower Management. 1997;23(4-5):140-7.

9. Bridgewater $\mathrm{FH}$, Bridgewater KJ, Zeitz CJ. Using the ability to perform $\mathrm{CPR}$ as a standard of fitness: a consideration of the influence of aging on the physiological responses of a select group of first aiders performing cardiopulmonary resuscitation. Resuscitation. 2000;45(2):97-103.

10. Parkes KR. Shiftwork, job type, and the work environment as joint predictors of healthrelated outcomes. Journal of Occupational Health Psychology. 1999;4(3):256-68.

11. Webster AL, Horne L, Wheelans L, Bell GJ. Physical and physiological characteristics of elite ringette players. Sports Medicine, Training and Rehabilitation. 1999;9(1):25-40.

12. Davis PO, Dotson CO, SantaMaria DL. Relationship between simulated firefighting and physical performance measures. Med Sci Sports Exerc. 1982;14:65-71.

13. Leger LA, Mercier D, Gadoury C, Lambert J. The multistage 20 metre shuttle run test for aerobic fitness. J Sports Sci. 1988 Summer;6(2):93-101.

14. Jackson AS, Pollock ML. Steps toward the development of generalized equations for predicting body composition of adults. Canadian Journal Applied Sport Science. 1982 Sep;7(3):189-96.

15. Bangsbo J. Fitness training in football: A scientific approach. Bagsvaerd, Denmark: HO and Storm; 1994.

16. Goran M, Fields DA, Hunter GR, Herd SL, Weinsier RL. Total body fat does not influence maximal aerobic capacity. International Journal of Obesity Related Metabolic Disorders. 2000 Jul;24(7):841-8.

17. Van Hoeyweghen RJ, Verbruggen G, Rademakers F, Bossaert LL. The physiologic response of CPR training. Annals of Emergency Medicine. 1991;20(3):279-82.

18. Franklin BA, editor. ACSM's Guideline for exercise testing and prescription. 6th ed. Philadelphia: Lippincott Williams and Wilkins; 2000.

19. Craig BN, Congleton JJ, Kerk CJ, Lawler JM, McSweeney KP. Correlation of injury occurrence data with estimated maximal aerobic capacity and body composition in a highfrequency manual materials handling task. American Industrial Hygiene Association Journal. 1998;59(1):25-33. 
20. Elferink-Gemser MT, Visscher C, van Duijn MAJ, Lemmink KAPM. Development of the interval endurance capacity in elite and sub-elite youth field hockey players. 10.1136/bjsm.2005.023044. British Journal of Sports Medicine. 2006 April 1, 2006;40(4):340-5.

21. Wenger HA, Bell GJ. The interactions of intensity, frequency and duration of exercise training in altering cardiorespiratory fitness. Sports Medicine. 1986;3:346-56.

22. Wilson GJ, Newton RU, Murphy AJ, Humphries BJ. The optimal training load for the development of dynamic athletic performance. Medicine and Science in Sports and Exercise. 1993;25(11):1279-86.

23. Kraemer WJ, Adams K, Cafarelli E, Dudley GA, Dooly C, Feigenbaum MS, et al. American College of Sports Medicine Position Stand: Progression models in resistance training for healthy adults. Medicine and Science in Sports and Exercise. 2002;34(2):36480 .

24. Hoff J, Gran A, Helgerud J. Maximal strength training improves aerobic endurance performance. Scandinavian Journal of Medicine and Science in Sports. 2002;12:288-95.

\section{Acknowledgment}

The authors would like to express their gratitude to the St John Ambulance Australia officers that volunteered for this study. The cooperation of Mr Bill Thompson, Manager of the Counter Disaster Planning and Special Events Division of St John Ambulance Australia is also acknowledged.

This Article was peer reviewed for the Journal of Emergency Primary Health Care Vol.5, Issue 1, 2007 
Table 1. Physical profile of conventional and special operations ambulance officers

\begin{tabular}{|c|c|c|c|c|c|}
\hline & \multicolumn{5}{|c|}{ Officers } \\
\hline & \multirow{2}{*}{ Total } & \multicolumn{2}{|c|}{ Conventional } & \multicolumn{2}{|c|}{ Special Operations } \\
\hline & & Lower & Upper & Lowel & Upper \\
\hline \multicolumn{6}{|l|}{ Measurement } \\
\hline \multirow[t]{2}{*}{$\begin{array}{l}\text { Maximal Aerobic Capacity } \\
\left(\mathrm{ml} \cdot \mathrm{kg} \cdot \mathrm{min}^{-1}\right)\end{array}$} & \multirow[t]{2}{*}{$45.8 \pm 5.2$} & \multicolumn{2}{|c|}{$44.3 \pm 5.2 \dagger$} & \multicolumn{2}{|c|}{$48.2 \pm 4.7 \dagger$} \\
\hline & & 42.2 & 46.4 & 45.7 & 50.6 \\
\hline \multicolumn{6}{|l|}{ Anthropometry } \\
\hline \multirow[t]{2}{*}{ BMI } & $26.9 \pm 3.2$ & \multicolumn{2}{|c|}{$27.3 \pm 3.3 \dagger$} & \multicolumn{2}{|c|}{$26.3 \pm 2.2$} \\
\hline & & 26.0 & 28.6 & 24.6 & 28.0 \\
\hline \multirow[t]{2}{*}{$\%$ Body fat } & $18.3 \pm 4.6$ & \multicolumn{2}{|c|}{$20.2 \pm 4.3 *$} & \multicolumn{2}{|c|}{$15.3 \pm 3.9 *$} \\
\hline & & 18.9 & 22.8 & 13.8 & 17.8 \\
\hline \multicolumn{6}{|l|}{ Muscle Strength } \\
\hline \multirow[t]{2}{*}{ Grip Strength (kg) } & $52 \pm 9$ & \multicolumn{2}{|c|}{$51 \pm 8$} & \multicolumn{2}{|c|}{$56 \pm 9$} \\
\hline & & 47.6 & 54.4 & 49.9 & 59.6 \\
\hline \multirow[t]{2}{*}{ Abdominal Stage } & $4 \pm 1$ & \multicolumn{2}{|c|}{$4 \pm 1$} & \multicolumn{2}{|c|}{$5 \pm 1$} \\
\hline & & 3 & 4 & 4 & 5 \\
\hline \multicolumn{6}{|l|}{ Muscle Endurance (60 s) } \\
\hline \multirow[t]{2}{*}{ Sit-up } & $21 \pm 11$ & \multicolumn{2}{|c|}{$19 \pm 11$} & \multicolumn{2}{|c|}{$23 \pm 10$} \\
\hline & & 14 & 24 & 18 & 28 \\
\hline \multirow[t]{2}{*}{ Push-up } & $40 \pm 12$ & \multicolumn{2}{|c|}{$36 \pm 10 *$} & & 1 * \\
\hline & & 32 & 41 & 41 & 53 \\
\hline Pull-up & $7 \pm 5$ & & & & \\
\hline & & 3 & 7 & 5 & 11 \\
\hline Muscle Power (cm) & $47.5 \pm 5.3$ & & 5.6 & & 4.4 \\
\hline & & 44.5 & 49.2 & 46.6 & 51.3 \\
\hline Flexibility (cm) & $32.6 \pm 8.7$ & 30.2 & $8.0 \dagger$ & & $8.6 \dagger$ \\
\hline & & 27.0 & 33.4 & 31.5 & 41.3 \\
\hline Agility & & & & & \\
\hline Fastest ( s ) & $7.45 \pm 0.38$ & 7.4 & 0.40 & & 0.32 \\
\hline & & 7.3 & 7.6 & 7.2 & 7.6 \\
\hline Average ( s ) & $7.96 \pm 0.48$ & 8.0 & 0.54 & & 0.34 \\
\hline & & 7.8 & 8.2 & 7.7 & 8.0 \\
\hline Fatigue Index & $13.7 \pm 7$ & 15.7 & $8.2 *$ & & $2.4 *$ \\
\hline & & 12.4 & 19.0 & 9.1 & 11.7 \\
\hline
\end{tabular}

Conventional officers $n=18$; Special Operations officers $n=11$

Lower and Upper 90\% Confidence intervals

* Significantly different between work situation $(\mathrm{P}<0.05)$

† Significantly different to an aged-based population mean $(\mathrm{P}<0.05)$

Author(s): D. Chapman, J. Peiffer, C. R. Abbiss \& P. B. Laursen 